\title{
In vitam et post-mortem: expressões de gratidão a Derek de Solla Price em agradecimentos e obituários acadêmicos
}

\author{
In vitam et post-mortem: expressions of gratitude to Derek de Solla Price in acknowledgments and academic
} obituaries

\author{
Maria Cristina Piumbato Innocentini Hayashi \\ Universidade Federal de São Carlos. Departamento de \\ Ciência da Informação, Brasil \\ dmch@ufscar.br \\ (iD) https://orcid.org/0000-0003-1250-3767
}

\author{
Alexandre Masson Maroldi \\ Universidade Federal de Rondônia. Departamento de \\ Ciência da Informação, Brasil \\ alexandre@unir.br
}

iD https://orcid.org/0000-0002-6592-7750

Carlos Roberto Massao Hayashi

Universidade Federal de São Carlos. Departamento de

Ciência da Informação, Brasil

massao@ufscar.br

iD https://orcid.org/0000-0003-1481-5545

\begin{abstract}
Resumo:
No processo de comunicação da ciência as expressões de gratidão por contribuições dadas e recebidas pelos pares podem revelar o reconhecimento científico àqueles que de alguma forma contribuíram com determinada pesquisa e com o avanço do conhecimento em uma área específica. Nesse contexto, o objeto de estudo deste artigo são os agradecimentos e obituários acadêmicos publicados em periódicos científicos, com o objetivo de analisar a presença do colégio invisível e a colaboração científica de Derek de Solla Price nessas publicações. A metodologia adotada combinou as análises bibliométrica e de conteúdo. A fonte de dados foi o Google Scholar e o corpus da pesquisa foi composto por artigos $(\mathrm{n}=46)$ contendo agradecimentos, e obituários, tributos e homenagens póstumas $(n=26)$ a Price. As seguintes variáveis foram analisadas: autores e autorias, evolução temporal dos artigos, títulos dos periódicos e áreas de conhecimento dos agradecimentos e obituários acadêmicos. Os resultados revelaram que o colégio invisível e a rede de colaboração científica de Price foram compostas por autores dos campos da cientometria, sociologia da ciência e história da ciência e da tecnologia.
\end{abstract}

Palavras-chave: Derek de Solla Price, Agradecimentos, Obituários acadêmicos, Colaboração científica, Colégio invisível.

\section{Abstract:}

In the science communication process, expressions of gratitude for contributions given and received by peers can reveal scientific recognition to those who somehow contributed to a certain research and to advance knowledge in a specific area. In this context, the object of study of this article is the acknowledgments and academic obituaries published in scientific journals, with the aim of analyzing the presence of the invisible college and the scientific collaboration of Derek de Solla Price in these publications. The adopted methodology combined bibliometric and content analysis. The data source was Google Scholar and the research corpus consisted of articles $(n=46)$ containing acknowledgments and academic obituaries $(n=26)$ to Price. The following variables were analyzed: authors and authors, time evolution of articles, titles of journals and areas of knowledge of acknowledgments and academic obituaries. The results revealed that Price's invisible college and scientific collaboration network were composed of authors from the fields of scientometry, sociology of science and history of science and technology.

KEYWORDS: Derek de Solla Price, Acknwledgements, Academic obituaries, Scientific collaboration, Invisible college. 


\section{INTRODUÇÃo}

Gratitude is like credit; it is the backbone of our relations; frequently we pay our debts not because equity demands we should, but to facilitate future loans. (La Rochefoucauld, 1917 [1851], p. 49).

No processo de comunicação científica, o ato de agradecer em uma publicação traz implícita a ideia de pagamento por um débito intelectual contraído ou pelas contribuições recebidas, de tal modo que enquanto as citações são expressões formais das dívidas adquiridas durante o desenvolvimento da pesquisa, os agradecimentos são expressões pessoais ou privadas de apreço pelas contribuições recebidas, conforme expostos nos estudos de (ordem cronológica): Kaplan (1965), Patel (1973), Heffner (1979), Kochen (1987), Cronin (1991, 1995), McCain (1991).

Enquanto parte integrante do sistema de recompensas da ciência (Merton, 1973) os agradecimentos podem iluminar as atividades de colaboração científica que usualmente não são reveladas pela análise de coautoria, e desse modo podem ser entendidos como uma espécie de capital simbólico (Bourdieu, 1975). Como referem Desrochers et al (2018, p. 17) os quadros bourdieusiano e mertoniano fornecem "uma weltanschauung que permeia a illusio acadêmica hoje, talvez mais do que nunca: acumular capital científico para conseguir a legitimação e a consagração no campo por meio da produção de conhecimento e do reconhecimento dessa contribuição por seus pares".

Conforme já observaram Price (1963), Crane (1972) e Merton (1988) desde há muito os cientistas pertencem a "colégios invisíveis" informalmente constituídos, ou a microambientes cognitivos, de tal forma que uma pessoa isolada constrói apenas sonhos, alegações e sentimentos, mas não fatos, como refere Latour (1987).

Esse fenômeno foi abordado por Cronin (2004) em um artigo cuja tradução literal do título - "Jogando boliche sozinho e junto" - é uma paráfrase ao clássico livro de Robert Putnam (2000) que analisou o declínio do capital social na vida americana contemporânea. Essa metáfora foi utilizada de modo inverso ("sozinho" em contraposição a "junto") para mostrar que no campo da ciência, contrariamente ao que ocorre na esfera pública, a cooperação e a colaboração ("boliche juntos”) se tornaram mais comuns que a pesquisa individual do século XX, de tal forma que o "lobo solitário da pesquisa em breve poderá figurar na lista de espécies ameaçadas" (Cronin, 2004, p. 557).

$\mathrm{O}$ aumento no número de autorias múltiplas em todas as áreas de conhecimento, até mesmo nas ciências humanas, cujas práticas de publicação tradicionalmente têm sido de autoria única, são um sinal de comprovação desse fenômeno. Contudo, na visão de Cronin (2004), a autoria única não é um sinônimo de confinamento intelectual solitário, uma vez que os autores estão enredados em uma rede sociocognitiva que envolve vários colegas, para os quais são enviados trabalhos e projetos para comentar o assunto em um nível privado, antes da apresentação e revisão editorial. Ou seja, a colaboração não se dá apenas por meio das estruturas formais e ferramentas sofisticadas, mas também é fruto da interação com colegas dentro e fora das instituições e acontece nas comunicações informais que geralmente são imperceptíveis e difíceis de serem detectadas e mensuradas.

Dessa perspectiva, o estudo dos agradecimentos está inserido no campo da colaboração científica, pois juntamente com as autorias e citações integram o "triângulo da recompensa" (Cronin \& Weaver, 1995) e descrevem os modos formais de comunicação acadêmica.

Por sua vez, agradecimentos em artigos científicos a colegas e pares acadêmicos, por suas contribuições ao trabalho relatado, trazem implícitas declarações de débitos intelectuais e de reconhecimento àqueles que colaboraram com o autor da pesquisa. Do ponto de vista funcional os agradecimentos transmitem um reconhecimento público por gestos essencialmente privados de assistência, os quais contribuíram de alguma forma para a pesquisa. O recebimento de créditos por meio dos agradecimentos também significa que a pessoa a quem se agradece não teve uma participação direta na produção do trabalho em questão, 
mas pode ter contribuído de outras maneiras, por exemplo, com a leitura crítica do texto preliminar, a indicação de referências relevantes para a pesquisa, ou oferecendo sugestões, comentários e incentivos ao autor. Algumas dessas contribuições, obviamente, são de natureza relativamente menor, mas outras podem exercer um importante efeito formativo para aqueles que as receberam, permitindo aos autores que os formulam expressar valores como gratidão, generosidade e modéstia.

Essas contribuições se tornaram mais institucionalizadas no processo de comunicação científica refletindo a crescente complexidade cognitiva, social e estrutural da pesquisa contemporânea, e intensificaram a dependência de assessores acadêmicos de confiança, conforme estabeleceu Cronin (2001). O aumento observado nos agradecimentos é, em certa medida, "em função de uma valorização da maturação do significado instrumental e normativo da prática dentro da academia"; e também, por causa da "crescente complexidade cognitiva, social e estrutural da pesquisa contemporânea, fatores esses que intensificam a 'dependência' de assessores acadêmicos de confiança”' (Cronin, 2001, p. 432).

Os agradecimentos também podem revelar uma rede social da qual o autor faz parte e a quem se dirige em momentos diferentes para obter apoio, conselho ou crítica construtiva antes de lançar seu trabalho ao escrutínio público. Contudo, os padrões de agradecimentos estão sujeitos às diferentes práticas disciplinares. Ao expor as redes pessoais e lugares a que pertencem os autores nas diferentes fases de sua vida profissional, os agradecimentos também podem revelar as regras de engajamento que definem a dinâmica de colaboração e interdependência entre os pesquisadores. Desse modo, os leitores podem observar que por trás da fachada cuidadosamente construída dos textos de pesquisa existe um autor com uma identidade real envolvida em uma rede de relações pessoais e acadêmicas.

Em resumo, ao registrarem as múltiplas contribuições para uma pesquisa relatada, a prática dos agradecimentos revela o reconhecimento científico por estímulos recebidos e incluem uma rica mistura que levam em conta sua natureza (recursos, procedimentos, conceitos) e tipos de apoios recebidos de diferentes agentes (financeiro, moral, administrativo, técnico ou instrumental, inspiracional, dos participantes da pesquisa, e da comunicação interativa entre pares), conforme exposto nos estudos de McCain (1991) e de Cronin (1991; 1995), bem como em estudos posteriores de Cronin, McKenzie \& Rubio (1993), Cronin, Shaw \& La Barre (2003, 2004), Hayashi \& Bello, (2014) e Hayashi (2018).

Por sua vez, a publicação de homenagens póstumas e tributos a colegas falecidos sob a forma de obituários, geralmente realizados por pares acadêmicos em periódicos científicos, contribuem para a consagração de biografias científicas e podem revelar traços de caráter, trabalho árduo e dedicação à vida acadêmica. Em certo sentido, essas homenagens costumam representar aqueles que são considerados líderes intelectuais em sua disciplina, ou seja, uma figura respeitada e inspiradora (Hamann, 2016; Macfarlane \& Chan, 2014).

Do ponto de vista da sociologia da ciência, os obituários acadêmicos também podem ser considerados como parte integante do sistema de recompensas da ciência operando dentro de um quadro cognitivo e moral que visa pagar dívidas intelectuais por meio do reconhecimento (Merton, 1973), tal como acontece com as formas de capital simbólico, entre elas a notoriedade intelectual e o prestígio científico, presentes na comunidade científica (Bourdieu, 1996).

Ao colocar em relevo a trajetória científica e os estágios da produção teórica dos falecidos, os temas de estudos que privilegiaram em suas trajetórias acadêmicas, bem como suas contribuições para a construção do conhecimento em sua área de atuação, os obituários acadêmicos podem ser considerados uma espécie de biografia póstuma. Essa narrativa biográfica, ao destacar um conjunto de atributos, valores e virtudes pessoais e acadêmicas do falecido favorece a formação de reputações, ainda que sob um viés de avaliação e reconhecimento post-mortem. Ou seja, ao expor traços de predeterminação do sucesso acadêmico, de trabalho árduo e dedicação à vida acadêmica, os obituários podem ser vistos como avaliações acadêmicas não oficiais dos mortos por seus pares.

Essas breves considerações teóricas sobre os agradecimentos e os obituários acadêmicos publicados em periódicos científicos servem de pano de fundo para introduzir a questão de pesquisa que se propôs a 
investigar nesse artigo: quais são as expressões de gratidão a Derek de Solla Price presentes nos agradecimentos e obituários acadêmicos e como elas revelam a sua contribuição e colaboração científica na literatura publicada antes e após a sua morte? Com base nessa problemática a hipótese da pesquisa foi a de que as expressões de gratidão presentes nos agradecimentos e os obituários acadêmicos de Price constituem-se em documentos privilegiados que materializam o fenômeno do colégio invisível e a colaboração científica na ciência.

Justifica-se a escolha de Price (1922-1983), esse notável cientista e físico teórico por formação que durante sua trajetória acadêmica enveredou por várias áreas de conhecimento, em particular a história da ciência e da tecnologia, e a ciência da informação. Um exemplo sua expertise em vários campos de conhecimento é reconhecida por ele mesmo ao revelar a Beaver (1985, p. 385):

Fico fascinado por estar totalmente absorvido em usar todos os tipos de técnicas para resolver os problemas e então, por completo, dar palestras, escrever e ensinar sobre eles. Grande parte da motivação deve ser devida a uma espécie de síndrome do diletante bem-sucedido que sempre me fez sentir que o campo do outro sujeito pode ser mais excitante do que o meu. Assim, eu me deleito em ser reconhecido publicando como um sociólogo, historiador, arqueólogo, entrando em um jornal de antropologia ou medicina, sendo citado como um especialista em serviços de informação científica ou política científica, ou mesmo por retornar à minha formação original como matemático ou físico experimental. O que quer que alguém me diga que eles fazem, parece que tenho alguma compulsão para igualar isso de alguma forma, para atingir um acorde de simpatia e competir.

Sua relevante contribuição aos estudos métricos da ciência lhe valeu o epônimo de "pai da Cientometria” (Merton \& Garfield, 1987). A publicação de Little Science, Big Science (Price,1963) sua opus magnum foi seguida por inúmeros outros textos de igual relevância (Garfield, 2007) para os campos da cientometria e sociologia da ciência, e que são mandatórios para aqueles que desejam compreender o significado dos indicadores bibliométricos e cientométricos nas políticas científicas e as intricadas relações entre ciência, tecnologia e sociedade. Como destacou Bonitz (1994, p. 6), Price foi "a pessoa que provocou e estimulou os nossos sentimentos e reflexões sobre os estudos quantitativos da ciência”.

Somado a essas justificativas está o fato de que foi Price $(1963,1986)$ quem articulou a noção de "colégio invisível" para designar o fenômeno que acontece em grupos de pesquisadores de elite que a despeito da existência de distância geográfica, interagem mutuamente para a troca produtiva de ideias e informações e para o monitoramento do progresso científico em seus campos de conhecimentos.

Dessa perspectiva, o papel de Price como leitor privilegiado de manuscritos de colegas antes que fossem submetidos à publicação, conforme seria revelado posteriormente pelos autores nos agradecimentos dos artigos publicados, pode ser encarado como uma evidência da comunicação interativa entre pares no colégio invisível. Como referiu Crawford (1971, p. 304), “o 'colégio invisível' hipotetizado por Price é em parte uma noção intuitiva da 'conectividade' dos cientistas na comunicação de informações, nas fronteiras de um campo ativo da ciência".

De certa forma, o conceito de colégio invisível também está presente nos obituários de Price, tanto naqueles publicados imediatamente após a sua morte, como nas homenagens e tributos póstumos ocorridos no transcurso dos aniversários de sua morte para celebrar o seu legado e manter viva a relevância de seus trabalhos. Nas palavras de Garfield (1984, p. 213), “a morte se torna mais predominante à medida que envelhecemos e acumulamos colegas em todo o mundo. Esse é o preço que os estudiosos devem pagar pelo privilégio de serem aceitos em um colégio invisível".

Uma motivação adicional para a realização da pesquisa levou em consideração que a despeito do importante papel dos agradecimentos no processo de comunicação interativa entre os pares, e dos obituários acadêmicos, tributos e homenagens àqueles que fizeram relevantes contribuições para o desenvolvimento científico de suas áreas de conhecimento, esses objetos de estudo ainda têm despertado pouco interesse na comunidade bibliométrica e cientométrica brasileira. Essa desatenção não reflete falta de importância, pois os agradecimentos, os obituários e as homenagens póstumas podem gerar informações significativas sobre a colaboração no processo de produção e transmissão do conhecimento científico. Desse modo, esse artigo 
pode contribuir para gerar novas percepções a partir de perspectivas pouco exploradas no campo da ciência da informação.

Tendo em vista esses pressupostos, o estudo realizado teve como objetivo analisar a presença do colégio invisível e da colaboração científica de Price expressas em agradecimentos, obituários, homenagens e tributos póstumos acadêmicos publicados em periódicos científicos.

\section{Metodologia}

Do ponto de vista da caracterização da pesquisa trata-se de um estudo de natureza bibliográfica (Pizzani, Silva \& Hayashi, 2012) utilizada para constituir o referencial teórico, e que foi complementada com a pesquisa documental, pois selecionou como fonte de dados artigos publicados que ainda não tiveram tratamento científico e analítico. A pesquisa combinou as abordagens metodológicas da análise bibliométrica e da análise de conteúdo visando fortalecer a validade dos resultados conforme recomendam Silva, Hayashi y Hayashi (2011).

A seleção e análise do corpus da pesquisa foram orientadas pelos seguintes procedimentos:

1) Coleta de dados no Google Scholar escolhido por ter se tornado nos últimos anos um poderoso banco de dados da literatura acadêmica com livre acesso na Web, contendo cerca de 389 milhões de registros de publicações científicas de diversos campos de conhecimento web (Gusenbauer, 2019; Halevi, Moed \& BarIlan, 2017). A coleta de dados ocorreu no período entre setembro e outubro de 2020 mediante a combinação dos seguintes termos de busca "Derek de Solla Price", "acknowledgment", "support”, "advice”, "comments", "eloge", "obituary", "tribute". As buscas terminaram ao ser atingido ponto de saturação, isto é, quando os registros obtidos passaram a apresentar certa redundância ou repetição devido à falta de relevância dos dados conduzindo ao fechamento amostral. Fixou-se como critérios de inclusão apenas a tipologia "artigos" sem restrição temporal e de idiomas, e como critérios de exclusão, texto completo sem acesso e aqueles que não se adequavam ao escopo da pesquisa. Após a coleta de dados foram identificados 730 registros. Depois da aplicação dos critérios de inclusão e exclusão o corpus amostral da pesquisa $(\mathrm{n}=72)$ foi constituído por artigos com agradecimentos $(n=46)$ publicados no período entre 1966 e 1990, e obituários $(n=26)$ publicados entre 1983 e 2008. Esse corpus representa aproximadamente $10 \%$ do total de registros encontrados $(\mathrm{n}=730)$.

2) leitura integral dos artigos com agradecimentos e dos obituários e definição das seguintes categorias de análise: a) agradecimentos: autores (nomes e gênero), tipos de autoria (individual ou coautoria), evolução temporal dos artigos com agradecimentos, periódicos (títulos e áreas de conhecimento), tipos de agradecimento; tipos de apoio recebido nos agradecimentos do tipo comunicação interativa entre os pares; b) obituários: autores (nome e gênero); tipos de autoria (individual ou coautoria); evolução temporal dos obituários, homenagens e tributos póstumos; periódicos (títulos e área de conhecimento); valores e virtudes acadêmicas expressas nos obituários.

3) elaboração do portfólio de dados em um arquivo Excel contendo variáveis relacionadas às categorias de análise estabelecidas após a leitura integral dos textos dos agradecimentos e obituários.

4) descrição dos dados obitidos representados por indicadores quantitativos e qualitativos.

5) análise e interpretação dos resultados baseadas no referencial teórico da Bibliometria e da Sociologia da Ciência.

\section{Resultados E discussão}

Os resultados da pesquisa sobre as expressões de gratidão a Price manifestadas em agradecimentos e obituários foram subdivididos em duas subseções visando uma melhor exposição e discussão dos achados da pesquisa. 


\title{
3.1 Os agradecimentos a Derek de Solla Price (1966-1990)
}

\author{
In many cases, the acknowledgement functions as a kind of \\ closet citation. It almost begs to be taken out, dusted down and \\ put to good use. (Cronin, 1992, p. 25)
}

Os artigos $(\mathrm{n}=46)$ com agradecimentos a Price cobrem um intervalo de 24 anos e foram publicados entre 1966 e 1990. A Figura 1 apresenta a distribuição dos artigos publicados em dois períodos: o primeiro, antes de sua morte, entre 1966 e 1983, e o segundo, após a sua morte, entre 1984 e 1990.

Figura 1 - Distribuição dos artigos com agradecimentos a Derek de Solla Price, 1966-1990.

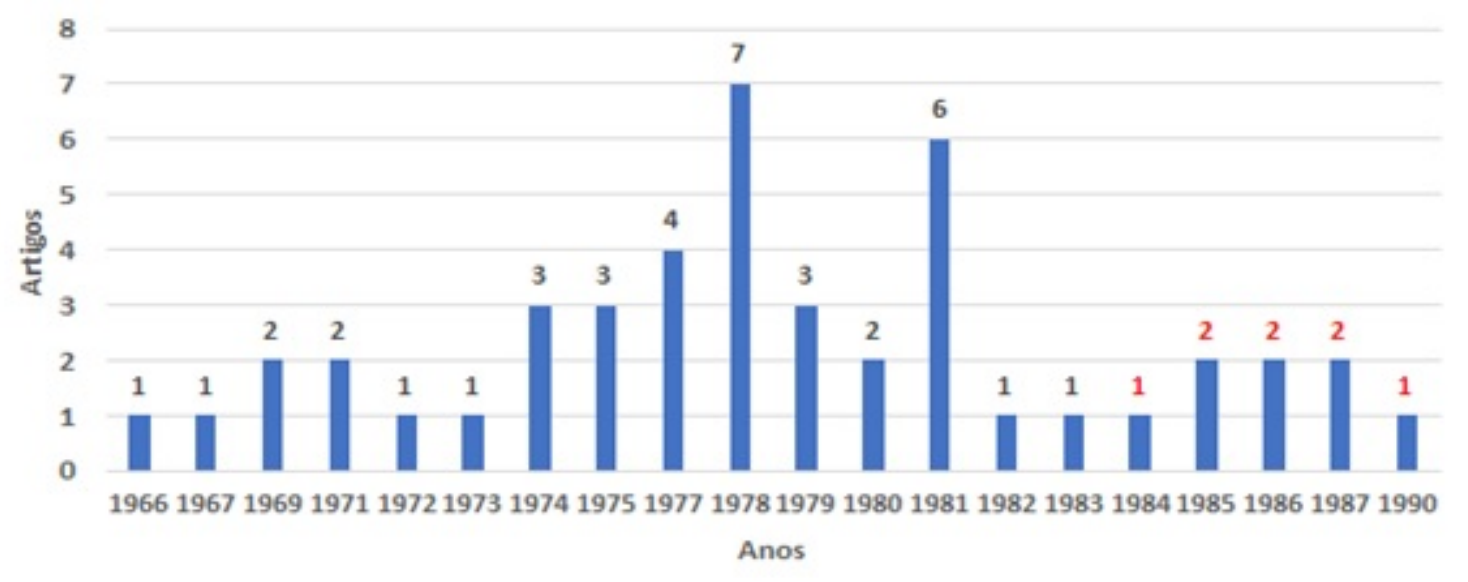

Fonte: elaborada pelos autores.

Observa-se que a média anual $(\mathrm{n}=2,3)$ de artigos com agradecimentos é estável apresentando poucas oscilações. Há um ligeiro aumento nos anos de 1974, 1975 e 1979 (n=3) e no ano de $1977(n=4)$ e quase dobrou nos anos $1978(n=7)$ e $1981(n=6)$. Nota-se que a maioria $(n=38)$ dos artigos com agradecimentos foi publicada entre 1966 até o ano da morte de Price, em 1983. Uma possível explicação para os escores mais altos nesses anos talvez esteja relacionada à repercussão entre seus pares acadêmicos das principais obras sobre o desenvolvimento e a quantificação da ciência, publicadas por Price $(1961,1963,1965,1969,1971,1976)$ e por Price y Beaver (1966) estimulando novas reflexões e consequentemente promovendo a interlocução entre eles. Não por acaso, três artigos com agradecimentos a Price discutem os colégios invisíveis (Crane, 1969a, 1969b) e a comunicação informal entre os cientistas (Crawford, 1971) e fazem citações das obras de Price que abordam essas temáticas.

Após a morte prematura e inesperada de Price, a comunicação interativa com seus pares revelada nos artigos com agradecimentos decresce consideravelmente $(n=8)$ perdurando por mais seis anos no intervalo entre 1984 e 1990. Contrariamente aos agradecimentos a Price in vitam, o resquício dessa comunicação nesses anos pode ser considerado um reconhecimento post mortem.

Por exemplo, o artigo de Arunachalam y Singh (1984) é dedicado à memória de Price, a quem os autores agradecem por sua contribuição pioneira e inspiradora à cientometria. Rossiter (1986), que foi aluna de Price, também dedica seu artigo à memória de seu falecido professor. Vale mencionar que essa historiadora da ciência foi quem cunhou a expressão "Efeito Matilda" para descrever o fenômeno da sub-representação feminina na ciência, isto é, quando as contribuições de mulheres cientistas são ignoradas completamente ou creditadas aos seus colegas homens (Rossiter, 1993).

Diamond Jr. (1986) e de Rabkin (1987) agradecem pelos comentários de Price em artigos anteriores e pelas discussões que tiveram sobre o assunto, e Simms (1990) agradece pelos incentivos recebidos e às lembranças de viagem que ambos fizeram à Siracusa. 
Dentre os artigos com agradecimentos post mortem três merecem ser destacados. Cole y Meyer (1985, p. 457) lamentam profundamente "não ter concluído o trabalho a tempo de receber os comentários de Derek". Irvine y Martin (1985, p.308) comentam que a pesquisa relatada no artigo foi inicialmente contestada por muitos cientistas, e "durante esses tempos difíceis Derek de Solla Price prestou apoio e encorajamento aos autores, um ato pelo qual eles são extremamente gratos”. E no artigo de Dresch y Janson (1987, p.340) intitulado Giants, pigmies, and the social costs of fundamental research or Price revisited os autores agradecem a Price pela inclusão do subtítulo (Price revisited) que "foi sugerido não apenas por seu conteúdo, mas também pelo título de um capítulo ('Galton Revisited') do livro de Price Little science, big science". Além disso, o primeiro autor agradece a Price reconhecendo especialmente "os benefícios incalculáveis - pessoais e acadêmicos - de mais de uma década de associação próxima com Derek J. de Solla Price, Professor Avalon de História da Ciência na Universidade de Yale até sua morte em 1983”.

Em relação ao local de inserção dos agradecimentos nos artigos publicados importa ressaltar que cada periódico possui normas específicas a respeito. Desse modo, a localização dos agradecimentos nos artigos variou, pois a maioria $(\mathrm{n}=17)$ estava situada na primeira página do texto, em uma nota de rodapé inicial sem numeração, ou no parágrafo final $(n=8)$ do texto. Em outros artigos $(n=10)$ os agradecimentos foram inseridos em uma seção específica, destinada a essa finalidade. Os agradecimentos também foram colocados na seção de notas finais $(n=2)$ e de rodapé $(n=1)$, na seção de referências $(n=3)$ e nas seções de notas e referências $(\mathrm{n}=3)$. Também foram encontrados agradecimentos situados em locais incomuns, como no artigo de Van Helden (1977) inserido no corpo do texto, e no artigo de Goldsmith (1967) que foi colocado na fonte de tabelas extraídas de um relatório preliminar.

A Figura 2 apresenta os títulos de periódicos $(n=24)$ que publicaram os artigos com agradecimentos a Price.

Figura 2 - Periódicos com artigos de agradecimentos a Derek de Solla Price.

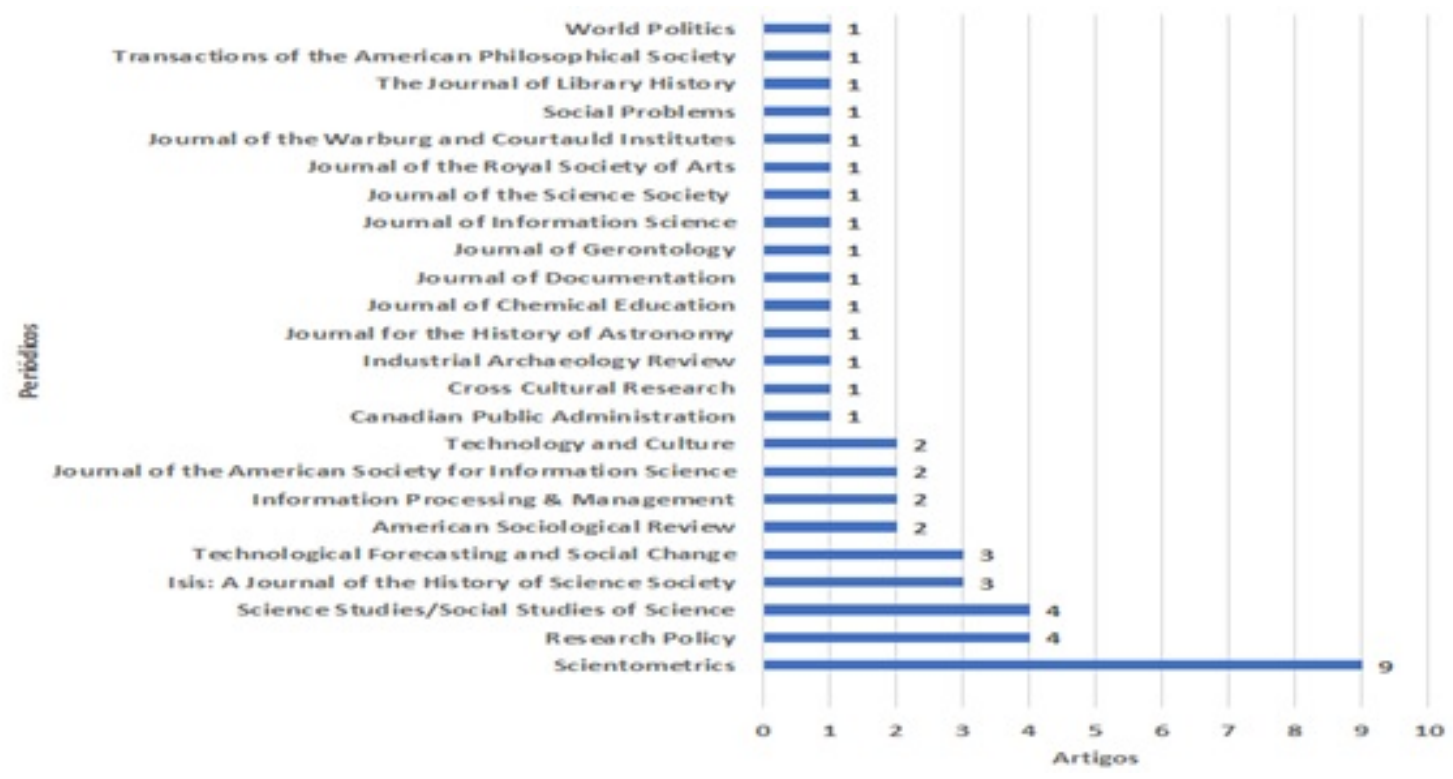

Fonte: elaboração dos autores.

O periódico Scientometrics publicou o maior número de artigos $(\mathrm{n}=9)$ seguido por Research Policy $(\mathrm{n}=4)$, Science Studies/Social Studies of Science $(\mathrm{n}=4)$, Isis: A Journal of the History of Science Society $(\mathrm{n}=3)$ e Technological Forecasting and Social Change $(\mathrm{n}=3)$. Outros periódicos $(\mathrm{n}=4)$ apresentaram dois artigos com agradecimentos cada: American Sociological Review, Information Processing \& Management, Technology and Culture. Os demais periódicos $(\mathrm{n}=15)$ publicaram apenas um artigo com agradecimentos.

A análise do escopo dos artigos com agradecimentos $(n=46)$ revelou que $39,1 \%(n=18)$ situam-se no campo da cientometria. O mesmo percentual foi alcançado pelos artigos $(n=18)$ da área de sociologia da 
ciência, e os demais ( $\mathrm{n}=10)$ estão relacionados ao domínio da história da Ciência e da tecnologia. Essas são as três áreas para as quais Price dedicou substancialmente seus esforços de pesquisa, portanto não constitui surpresa que os agradecimentos publicados em periódicos desse campo venham de colegas dessas disciplinas.

Pode-se supor, portanto, que os autores $(n=57)$ que agradeceram a Price nos artigos analisados $(n=46)$ faziam parte de um colégio invisível composto por "um grupo de no máximo 100 colegas" (Price, 1963, p.73) conforme sua definição.

Em relação às autorias dos artigos com agradecimentos prevaleceu a autoria individual $(n=31)$, seguida por artigos $(n=12)$ com dois autores, três autores $(n=1)$ e quatro autores $(n=2)$. Quanto ao gênero dos autores $(n=57)$ que fizeram agradecimentos a Price, os resultados obtidos revelaram a predominância de autorias masculinas $(n=51)$ em comparação com as autorias femininas $(n=6)$.

Os autores mais frequentes $(n=6)$ que fizeram agradecimentos a Price, tanto em artigos individuais como e em coautoria, foram Michael Moravcsik $(n=4)$, Yakov Rabkin $(n=3)$, Diane Crane $(n=2)$, Joel Cohen $(\mathrm{n}=2)$, Theodore Gordon $(\mathrm{n}=2)$ e Herbert Inhaber $(\mathrm{n}=2)$. Também foram identificados outros autores que são referência nos campos da sociologia da ciência, da cientometria, e da história da ciência e da tecnologia, entre eles Donald de Beaver, Stephen Cole, Susan Crawford, Margaret Rossiter, Belver Griffith, John Irvine, Ben Martin, Manfred Kochen, Michael Moravcsik, Paul Kantor, Arthur J. Meadows, Maurice Goldsmith e Francis Narin.

Para identificar a tipologia dos agradecimentos a Price foram utilizadas as classificações formuladas nos estudos de McCain (1991), Cronin (1991, 1995), Cronin, Shaw y La Barre (2004), Hayashi y Bello (2014) e Hayashi (2018).

A maioria dos agradecimentos (n=27) a Price é do tipo “comunicação interativa entre pares", isto é, aqueles que demonstram o reconhecimento pelas análises críticas a colegas do mesmo nível hierárquico que atuam como caixas de ressonância e são fontes de inspiração e novas ideias.

Com menor representatividade foram identificados os agradecimentos de "apoio moral" $(\mathrm{n}=9)$ caracterizados como aqueles que abrangem o suporte institucional, o acesso a dados e informações relacionadas à pesquisa, a utilização de equipamentos, e o apoio de amigos e familiares. Esses agradecimentos de "apoio moral" (Cronin, 1991) aos colegas revela a generosidade intelectual de Price, e fazem parte de um conjunto de valores e virtudes acadêmicas que costumam ser valorizadas na comunidade científica.

Agradecimentos do tipo "apoio técnico" estão relacionados ao oferecimento de auxílio sobre revisão de manuscritos, análises estatísticas, acesso a instalações, equipamentos e recursos de informática. Apenas um agradecimento desse tipo foi identificado entre os artigos analisados. Por sua vez, um conjunto de artigos $(\mathrm{n}=9)$ apresentou mais de um tipo de agradecimento, isto é, "comunicação interativa entre pares" e "apoio técnico" ( $n=6)$ e "técnico" e "comunicação interativa entre pares" $(n=3)$.

Nos estudos de McCain (1991) e Cronin (1991) as várias formas de classificação da comunicação informal entre pares incluem o fornecimento de informações e sugestões específicas, comentários críticos sobre o manuscrito, conselhos recebidos e discussões ocorridas durante a realização da pesquisa, e inspiração e estímulos recebidos. Levando em conta essa categorização a Tabela 1 apresenta os tipos de apoio que revelam a comunicação interativa entre Price e seus pares. 
Tabela 1 - Tipos de apoio de Derek de Solla Price revelados nos artigos.

\begin{tabular}{l|c}
\hline \multicolumn{1}{c|}{ Tipos de apoio } & Artigos \\
\hline Leitura crítica de versões anteriores do manuscrito & 14 \\
\hline Comentários críticos, sugestões e conselhos úteis & 13 \\
\hline Correspondência valiosa e estimulante & 5 \\
\hline Incentivo, encorajamento e influência & 5 \\
\hline Sugestões de referências & 3 \\
\hline Sugestões de subtítulo, terminologia, abordagem & 3 \\
\hline Discussões & 2 \\
\hline Acesso a dados & 2 \\
\hline Conversas frequentes & 1 \\
\hline Assistência generosa & 1 \\
\hline Contribuições na definição do plano de estudo, seleção de tecnologias, \\
técnicas de análise e interpretação dos dados & 1 \\
\hline Total & $\mathbf{5 0}$ \\
\hline
\end{tabular}

Fonte: elaboração dos autores.

Importa esclarecer que o somatório de artigos $(\mathrm{n}=50)$ da Tabela 1 é maior que o total de artigos analisados $(\mathrm{n}=46)$, pois um artigo pode incluir mais de um tipo de agradecimento.

\subsection{Os obituários, homenagens e tributos póstumos a Derek de Solla Price (1983-2008)}

La vita bene spesa, lunga é. (Leonardo da Vinci, 1970, p. 294).

Obituários, homenagens e tributos póstumos podem ser inseridos no contexto das narrativas biográficas post-mortem que reconstroem trajetórias de vida. Embora semelhantes enquanto gêneros textuais e nos sentidos que se quer dar à morte de um indivíduo, as diferenças entre eles podem ser buscadas no conceito de cada um. Por exemplo, os obituários, ou necrológios, são textos que informam o falecimento da pessoa geralmente apresentando uma seleção de fatos e episódios marcantes de sua vida. Ao contrário dos prêmios que são dados às pessoas vivas, as homenagens póstumas são uma forma de reconhecimento das obras daqueles que já faleceram demonstrando respeito, admiração e consideração. Por sua vez, os tributos póstumos são uma forma honrar a memória do falecido compartilhando momentos de sua vida e obra. Nesse artigo essa 
distinção não foi realizada, ou seja, foram considerados como "obituários" os artigos que além de noticiarem o falecimento de Price também prestaram homenagens e tributos póstumos a esse cientista e pesquisador.

Com base nesse entendimento, verificou-se que os obituários, homenagens e tributos póstumos $(\mathrm{n}=26)$ a de Price (Figura 3) foram publicados entre 1983 e 2008.

Figura 3 - Obituários, tributos e homenagens a Derek Solla Price, 1983-2008.

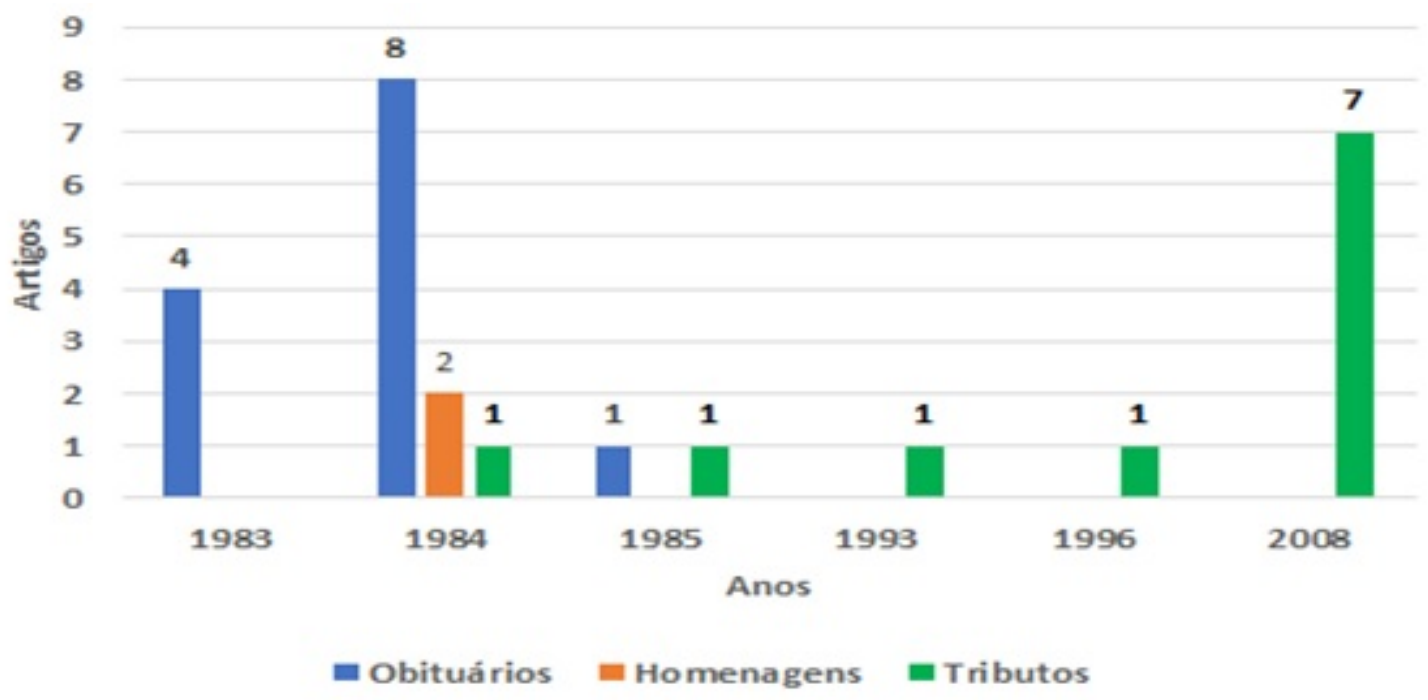

Fonte: elaboração dos autores.

Não é surpresa que os obituários $(\mathrm{n}=13)$ de Price tenham sido publicados no ano da sua morte $(\mathrm{n}=4)$ e nos dois anos subsequentes $(\mathrm{n}=9)$. Pode-se supor que tendo seu falecimento ocorrido em 3 de setembro de 1983, apenas há três meses do final daquele ano, isso impediu que os obituários fossem publicados rapidamente.

Dois obituários foram publicados como editoriais nas revistas Science and Public Policy (1983) e Scientometrics (1984). Outros obituários (Goldsmith, 1983, Griffith,1983) foram publicados na Science and Public Policy e na 4 S Review editada pela Society for Social Studies of Science. Esses periódicos contaram com a valorosa participação de Price na sua criação e participação no corpo editorial. No dia seguinte de sua morte foi publicado um obituário no The New York Times (1983), jornal da imprensa norte-americana que desde 1858 mantém uma coluna fixa de obituários de personalidades de destaque em diversas áreas e de pessoas comuns cujas vidas têm muito a oferecer e ganharam outra dimensão ao serem retratadas em suas páginas. $\mathrm{O}$ texto desse obituário é bastante breve e destaca as principais realizações científicas de Price nos vários campos em que atuou.

Os demais obituários $(\mathrm{n}=8)$ foram elaborados por pesquisadores dos campos da história da ciência e da tecnologia, sociologia da ciência, cientometria, e dos estudos sociais da ciência e da tecnologia, os quais além de terem tido o privilégio de conviver academicamente com Price também mantiveram com ele uma amizade pessoal, entre eles: Allan Mackay, Anthony Michaelis, Belver Griffith, Donald de Beaver, Eugene Garfield, Manfred Kochen, Eugene Garfield, Katherine McCain, Silvio Bedini, Susan Crawford.

Chama atenção entre os obituários aquele que foi elaborado pelo jornalista e editor científico Anthony R. Michaelis, amigo de longa data em cuja casa Price faleceu repentinamente, de ataque cardíaco, aos 61 anos. O obituário destaca as principais obras e as contribuições de Price que se estendem à história social da ciência, o presente futuro da ciência, às comunicações sobre a ciência na Nature, às medidas de citações, ao financiamento da ciência, à revolução técnico-científica mundial, entre outras. Para Michaelis (1984, p. 9) "seus muitos amigos, seus colegas em todo o mundo, seus alunos e aqueles que apenas o ouviram ou leram, sempre se lembrarão de Derek Price como um ser humano caloroso e um grande estudioso, um historiador onipresente e um cientista meticuloso". 
Além dos obituários também foram identificadas quatro homenagens e tributos póstumos publicados em 1984 e 1985 (Garfield, 1984, 1985; Griffith, 1984; Steinacker, 1984).

Outros tributos póstumos foram publicados mais tarde, na primeira metade dos anos 1990 e no final dos anos 2000. O primeiro, em 1993, após dez anos de seu falecimento (Chen, 1993). Em 1996, treze anos após a sua morte, o legado de Price à história da ciência, política científica, e cientometria foi exemplarmente analisado no artigo de Yagi, Badash y Beaver (1996). Nesse artigo, a autora e os dois demais autores, que foram alunos de Price, relembram a química dos primeiros anos do Departamento de História da Ciência e Medicina na Universidade de Yale, e refletem sobre suas experiências com o Price acadêmico, professor e mentor.

Em 2008, para marcar os 25 anos da morte, o periódico Research Trends publicou uma edição especial contendo sete artigos de renomados cientometristas (Anthony Van Raan, Eugene Garfield, Henry Moed, Katherine McCain, Leo Egghe, Loet Leydesdorff, Wolgang Glänzel) que haviam sido honrados com o recebimento da Medalha Derek de Solla Price - prêmio instituído em 1984 pela revisa Scientometrics destinado a pesquisadores com relevantes contribuições acadêmicas para o campo da cientometria - os quais relembraram suas memórias sobre o pai da cientometria e descreveram a influência que seu trabalho tiveram sobre eles.

Os obituários, tributos e homenagens póstumas a Price $(\mathrm{n}=26)$ foram publicados em diversos periódicos científicos $(\mathrm{n}=15)$ e em um jornal de grande circulação norte-americano (The New York Times), conforme mostram os dados da Figura 4.

Figura 4- Periódicos que publicaram obituários, homenagens e tributos.

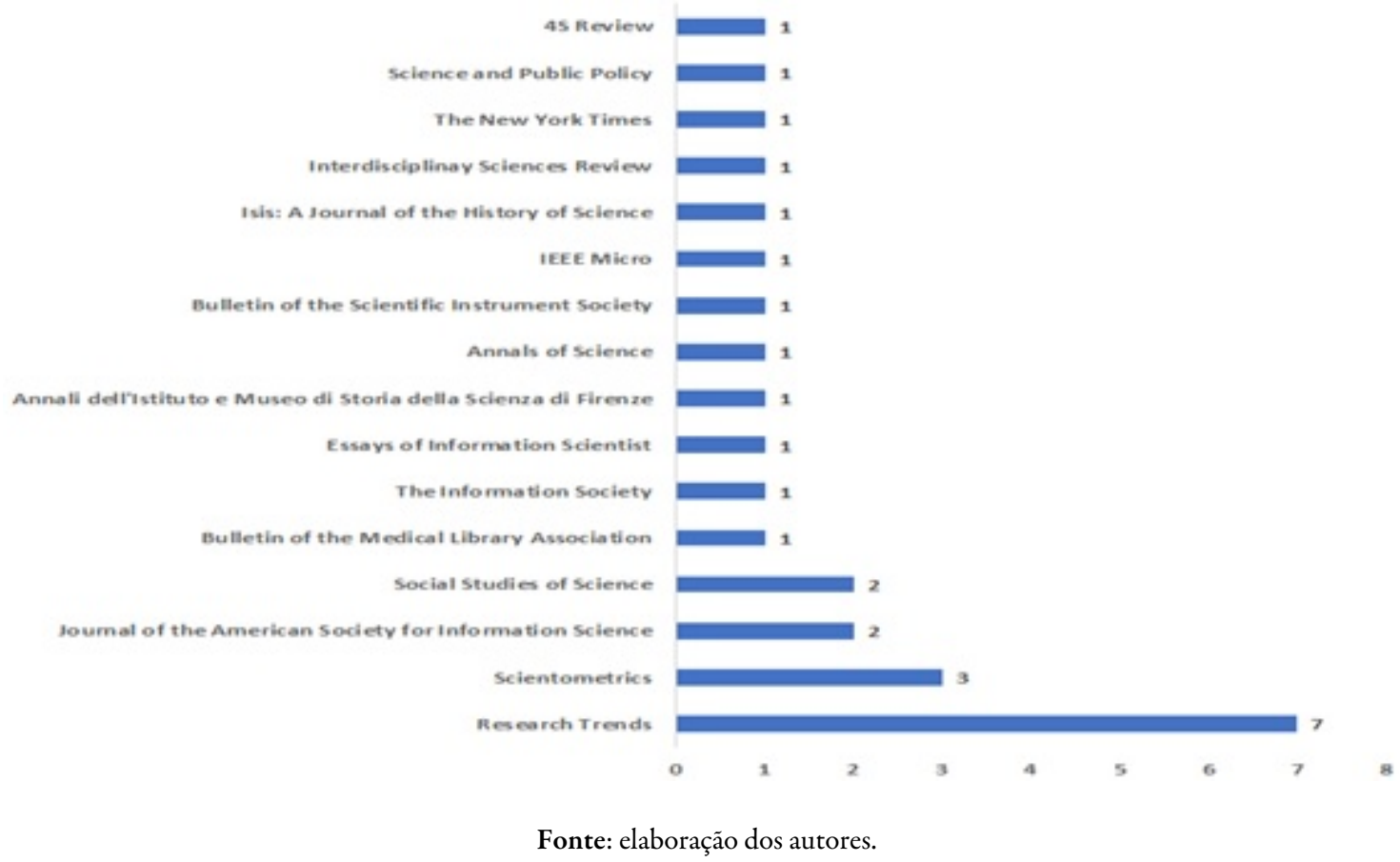

Entre os obituários, tributos e homenagens a Price a maioria $(\mathrm{n}=15)$ foram publicados em periódicos $(\mathrm{n}=6)$ da área de ciência da Informação, assim distribuídos: Research Trends $(\mathrm{n}=7)$, Scientometrics $(\mathrm{n}=3)$, Journal of the American Society for Information Science $(\mathrm{n}=2)$, The Information Society $(\mathrm{n}=1)$, Bulletin of the Medical Library Association ( $\mathrm{n}=1)$ e Essays of Information Scientist $(\mathrm{n}=1)$. Em seguida comparecem os periódicos $(\mathrm{n}=6)$ das áreas de História da Ciência e interdisciplinares com um artigo cada: Annali dell'Istituto e Museo di Storia della Scienza di Firenze, Annals of Science, Bulletin of the Scientific Instrument Society, Isis: A Journal of the History of Science, IEE Micro, Interdisciplinary Sciences Review. Por último, os periódicos ( $\mathrm{n}=3)$ 
das áreas de Estudos Sociais da Ciência e Sociologia da Ciênciaque juntos publicaram a minoria $(\mathrm{n}=4)$ dos artigos, a saber, Social Studies of Science $(\mathrm{n}=2)$, Science and Public Policy $(\mathrm{n}=1)$ e 4 S Review $(\mathrm{n}=1)$.

Em relação ao tipo das autorias dos artigos a maioria $(n=21)$ é individual, e apenas um em coautoria de três autores. Quanto ao gênero dos autores $(n=28)$ que publicaram obituários, tributos e homenagens a Price, a maioria são homens $(\mathrm{n}=22)$ e as mulheres $(\mathrm{n}=3)$ são minoria. Dessa contagem foram excluídos os artigos com autoria institucional publicados em editoriais $(\mathrm{n}=3)$ e no The New York Times.

A seguir são apresentados os principais valores, virtudes e atributos pessoais e acadêmicos de Price que foram destacados em alguns editoriais de periódicos científicos e pelos seus pares nos obituários, tributos e homenagens publicados, os quais exprimem a gratidão àquele que foi um influente mestre e intelectual, além de um generoso colega e amigo dedicado.

Quadro 1 - Valores e virtudes pessoais e acadêmicas de Derek de Solla Price.

\begin{tabular}{|c|c|}
\hline A utores/Ano & Excertos dos obituários, homenagens e tributos pós tum os \\
\hline $\begin{array}{l}\text { Beaver }(1985, \text { p. } 371 \text {, } \\
\text { 374) }\end{array}$ & $\begin{array}{l}\text { A hist́́ria da dència perdeu uma de suas figuras mais pro vocantes, dinámicas e influentes. (...) Nós, histbriadores da ciência e } \\
\text { colegas em campos relacionados, sentremos falta dele, de sua energia e entusiasmo, de sua empolgaçăo in telectual e visăo, } \\
\text { e de seu espirito inquie to e imag inativo, sempre sondando para estender os limites do conhecimento. }\end{array}$ \\
\hline Chen $(1993, p .279)$ & $\begin{array}{l}\text { Uma figura in fuente na sociedade da informaçăo, ele também encorajou gentilmente os jovens académicos, induindo este } \\
\text { autor. Embora já tenha passado uma década desde que ele se tornou parte da história, ainda sentimos sua forte influência na } \\
\text { atualidade. }\end{array}$ \\
\hline Craw bord (1984, p. 238) & $\begin{array}{l}\text { Derek John De Solla Price foi um daqueles cientistas cujo trabalho deixou sua marca em todos nós nas próissóes da } \\
\text { informaçăo. Sempre que encontramos conceitos como o colégio invisivel, o crescimento exponencial de publicaçóes e redes } \\
\text { de artigos, estamos em territbrio que ele explorou. }\end{array}$ \\
\hline $\begin{array}{l}\text { Social Studies of } \\
\text { Science, (1983, p. i) }\end{array}$ & $\begin{array}{l}\text { Ele bi um membro valioso do Conselho Edibrial de nossa revista em seus anos de formaçăo e um de énsor entusiástico da } \\
\text { Society for Social Studies of Science (4S). Sua presença estmula nte e provocadora fará muita falta. }\end{array}$ \\
\hline $\begin{array}{l}\text { Scientometrics (1984, p. } \\
\text { 3) }\end{array}$ & 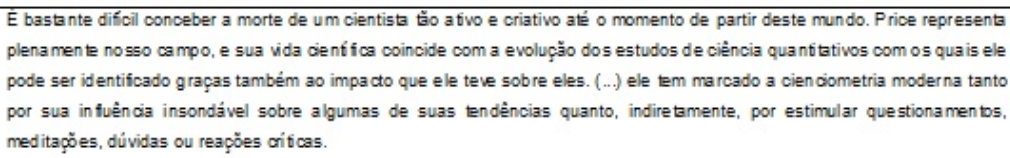 \\
\hline Egghe (2008, p. 4) & A universalida de da visăo de Solla a rice da clência da ciência infuenciou toda a min ha carreira de informetria. \\
\hline $\begin{array}{l}\text { Gar feld (1984, p. 271; } \\
\text { 1985, p. 501) }\end{array}$ & $\begin{array}{l}\text { A perd a dest homem estimulante e dinámico, de suas ideias e contribuiçoses, será sentida náo apenas por seus amigos, mas } \\
\text { por toda a comunida de cientifica. (...) Depois de tudo dito e feito sobre sua carreira, permanecerá um fato simples e gritante: } \\
\text { enquanto vivermos e trabalharmos neste campo em crescimento, nào apenas sentremos falta de Derek, mas seremos } \\
\text { lembrad os de seu impacto diariamente. Nesse sentido, ele se tornou imortal. }\end{array}$ \\
\hline Glänzel (2008, p.5) & $\begin{array}{l}\text { Fiquei chocado com seu falecimento inesperado e sent } c 0 \mathrm{mo} \text { se aquele dia significasse o encerramento de um capitivlo } \\
\text { importante na área. }\end{array}$ \\
\hline $\begin{array}{l}\text { Goldsmith (1983, p. } \\
318)\end{array}$ & Sentimos falta de seu riso contagian te, seu senso de diversăo e sua dignidade porque ele nunca foi pomposo. \\
\hline Grifith (1984, p. 5) & $\begin{array}{l}\text { Derek Price foi um colaborador importante para nossa visăo da céència como uma instituiçăo social e de seu papel na } \\
\text { sociedade. }\end{array}$ \\
\hline Kochen (1984, p. 148) & $\begin{array}{l}\text { A sua in fuéncia e memória serăo perpe tuadas pelas inúmeras pessoas que } \circ \text { finham em alta estima e } \infty \mathrm{m} \text { quem } \\
\text { desenvolveu bortes laços de afeto e respeito mútuo, bem como pelos seus alunos. }\end{array}$ \\
\hline Madkay (1984, p. 315) & Derek Price foi uma pessoa notável, uma das inteligências mais cria fivas de nossa época. \\
\hline MoCain $(2008, p .8)$ & $\begin{array}{l}\text { Nós, próessores e alunos da Drexel trabalhamos dentro a "tradiçáo priceana" de pesquisa ao longo de nossas carreiras } \\
\text { acadêmicas. }\end{array}$ \\
\hline Michaelis (1984, p. 9) & $\begin{array}{l}\text { Seus muitos amigos, colegas em todo o mundo, alun os e aqueles que apenas o ou viram ou leram, sempre se lembrarăo de } \\
\text { Derek Price como um ser humano caloroso e um grande estudioso, um historiador onipresente e um cientista mefouloso. }\end{array}$ \\
\hline Moed (2008, p. 9) & Minha pesquisa em estudos quantitativos de cléncia se ba seia fortemente no trabalho pioneiro de Derek de Solla Price \\
\hline Turner (1984, p. 107) & $\begin{array}{l}\text { Cheio de entusiasmo genero so e também de conhecimento, ele foi uma in spiraçáo para colegas em meu peque no campo de } \\
\text { pesquisa e, sem dú vida, em todo seu amplo campo de interesses. Por suas qualidades pessoais, fará muita falta. }\end{array}$ \\
\hline Van Raan (2008, p. 10) & As id eias e o trabalho de de Solla Price sempre foram uma das minhas maiores fontes de inspira çáo. \\
\hline $\begin{array}{l}\text { Yagi, Badash \& Beaver } \\
(1996, \text { p.64) }\end{array}$ & 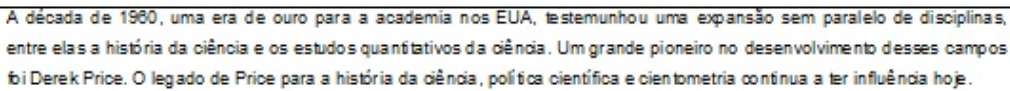 \\
\hline
\end{tabular}

Fonte: elaboração dos autores. 
Longe de destacar apenas aspectos positivos das relações de Price com colegas e alunos, os obituários também destacam traços de sua personalidade e método de trabalho que causavam certo desconforto para aqueles com quem se relacionava inicialmente, mas que se dissipavam ao longo da convivência, conforme comprovam essas passagens dos obituários:

Ele estava sempre disponível, aberto e encorajador, embora semana após semana, o que ele estava encorajando poderia mudar de acordo com sua fantasia recém-gerada (Beaver, 1985, p.374).

A partir dessa época, seu caráter agressivo gradualmente abrandou e suavizou. Ele se tornou um mentor e conselheiro visivelmente mais preocupado para estudantes e jovens acadêmicos em início de carreira (Beaver, 1985, p. 374).

E embora seu estilo provocador e desafiante causassem muitas sobrancelhas levantadas, sempre que ele era pego em uma comparação ou metáfora ultrajante, ele felizmente se corrigia. Quando a biografia definitiva de Derek Price for escrita, certamente notará seu talento para o dramático (Garfield, 1984, p. 217).

Às vezes descrito como um homem irreverente e determinado, seu estilo aguçado e inesperado frequentemente surpreendia os colegas ao longo dos anos (Bedini, 1984, p. 100).

Trabalhar no colégio invisível foi um dos pontos altos do trabalho de Beaver com seu mentor, que raramente publicou formalmente com outras pessoas, tendo apenas um punhado de outros colaboradores. Nesse sentido, Price era muito individualista na pesquisa (YagI, Badash \& Beaver, 1996, p. 71).

Ao exaltar as qualidades pessoais e acadêmicas de Price esses testemunhos de colegas e amigos que tiveram o privilégio de sua convivência oferecem mais do que um simples retrato de sua trajetória acadêmica, mas vão além ao destacar como seus exemplos continuam a ser fonte de inspiração nos vários campos de conhecimento em que atuou.

\section{ConClusões}

Nunca haverá outro Derek Price. É bom saber que outros ajudarão a iluminar os paradigmas que ele estabeleceu. (Garfield, 1984, p.216).

Ao finalizar esse artigo é possível afirmar que o colégio invisível e a rede de colaboração científica de Price estão presentes nos agradecimentos e obituários acadêmicos publicados em periódicos científicos e é representada por um conjunto de autores dos campos da Ccometria, sociologia da ciência e história da ciência e da tecnologia.

Alguns achados da pesquisa sobre os agradecimentos e obituários acadêmicos chamaram a atenção. Por exemplo, quando comparados os artigos com agradecimentos $(n=46)$ publicados entre 1966 e 1990, e os obituários, tributos e homenagens póstumas $(n=26)$ publicados entre 1983 e 2008, nota-se que a influência de Price estendeu-se 42 anos, desde o final da década de 1960 do século XX até a primeira década do século XXI. Esses resultados demonstram a importância e a longa permanência de suas contribuições para a ciência.

Por sua vez, o tempo médio entre o falecimento e a publicação de um obituário costuma ser curto, geralmente no dia ou na semana em que o evento ocorreu. Entretanto, no caso específico dos obituários acadêmicos isso não acontece, e os resultados da pesquisa mostraram que apenas quatro artigos foram publicados logo após a morte de Price. Entre esses, o fato do seu falecimento ter sido obituariado no The New York Times demonstra o prestígio e reconhecimento de Price enquanto membro destacado da comunidade científica norteamericana.

Além disso, observou-se que nos obituários publicados nos anos seguintes ao falecimento, principalmente os tributos e homenagens póstumas, a construção das narrativas sobre Price foi beneficiada por certo distanciamento que permitiu aos autores se beneficiarem de uma reflexão mais aprofundada sobre sua atuação nos campos de conhecimento nos quais estava inserido. Muitas vezes, essa reflexão também foi acompanhada 
de uma análise crítica da influência de Price na trajetória dos obituaristas e daqueles que prestaram suas homenagens e tributos.

Os agradecimentos, obituários, tributos e homenagens póstumas também cumprem um papel importante na preservação da memória científica. Nas expressões de gratidão contidas nesses textos, os pares científicos de Price reconhecem sua influência in vitam et post mortem e revivem aspectos de sua trajetória pessoal e acadêmica que são fonte de inspiração até nos dias atuais, ao mesmo tempo em que reforçam os laços de permanência de uma vida exemplar e o sentido de continuidade de obras tão necessária para o avanço do conhecimento científico.

Finalmente, é apropriado mencionar que no estudo realizado a seleção de uma única fonte de dados (Google Scholar) pode ter provocado um viés na composição do corpus investigado e em futuros estudos isso deve ser levado em consideração sugerindo-se que outras bases de dados sejam consultadas, de modo a incluir outros agradecimentos e obituários que possam ter ficado fora da amostra selecionada.

Longe da pretensão de esgotar a temática da gratidão e do reconhecimento científico expressos em agradecimentos e obituários acadêmicos, o estudo aqui exposto se constituiu em um exercício que pode suscitar outros olhares para novos objetos de investigação no campo dos estudos métricos da informação.

\section{REFERÊNCIAS}

Arunachalam, S. \& Singh, U. N. (1984). Publication \& citation patterns in literature of a high metabolism area: the case of superconductivity in 1970. Journal of information science, 8, 93-102.

Beaver, D. (1985). Isis. a journal of the history of science, 76(3), 371-374.

Bedini, S. A. Éloge: Derek de Solla Price (1922-1961). (1984). Annali dell'Istituto e Museo di Storia della Scienza di Firenze, 9, 95-115.

Bonitz, M. (1994). The multidimensional space of Scientometrics: the Derek John de Solla Price awards:1984-1993. Scientometrics, 29(1), 3-14.

Bourdieu, P. (1975). The specificity of the scientific field and the social conditions of the progress of reason. Social science information, 14(6), 19-47.

Bourdieu, P. (1996). The state nobility: elite schools in the field of power. Cambridge: Polity Press.

Chen, Z. (1993). Intelligence and discovery in an information Society: an essay in memory of Derek de Solla Price. The information society, 9(3), 277-280.

Cole, S.; Meyer, G. S. (1985). Little science, big science revisited. Scientometrics, 7(3-6), 443-458.

Crane, D. (1969a). Fashion in science:does it exist? Social problems, 16(4), 433-441.

Crane, D. (1969b). Social structure in a group of scientists: a test of the 'invisible college hypothesis'. American sociological review, 34, 335-352.

Crane, D. (1972). Invisible colleges: diffusion of knowledge in scientific communities. Chicago: University of Chicago Press.

Crawford, S. (1971). Informal communication among scientists in sleep research. Journal of the American Society for Information Science, 22, 301-310.

Crawford, S. (1984). Derek de Solla Price (1922-1983): the man and the contribution. Bulletin of the Medical Library Association, 72(2), 238-239.

Cronin, B. (1991). Let's the credits rolls: a preliminary examination of the role played by mentors and trusted assessors in disciplinary formation. Journal of documentation, 47(3), 227-239.

Cronin, B. (1992). Acknowledged but ignored: credit where credit is due. Bulletin of the American Society for Information Science, 18(3), 25.

Cronin, B. (1995). The scholar's courtesy: the role of acknowledgement in the primary communication process. London: 
Cronin, B. (2001). Acknowledgments trends in the research literature of information science. Journal of documentation, 57(3), 427-433.

Cronin, B. (2004). Bowling alone together: academic writing as distributed cognition. Journal of the American Society for Information Science and Technology, 55(6), 557-560.

Cronin, B., Mckenzie, G. \& Rubio, L. (1993). The norms of acknowledgement in four humanities and social sciences disciplines. Journal of documentation, 49(1), 29-43.

Cronin, B., Shaw, D. \& La Barre, K. (2003). A Cast of thousands: coauthorship and subauthorship collaboration in the 20th Century as Manifested in the Scholarly Journal Literature of Psychology and Philosophy. Journal of the American Society for Information Science and Technology, 54(9), 855-71.

Cronin, B., Shaw, D. \& La Barre, K. (2004). Visible, less visible, and invisible work: patterns of collaboration in 20th Century Chemistry. Journal of the American Society for Information Science and Technology, 55(2), 160-68.

Cronin, B. \& Weaver, S. (1995). The praxis of acknowledgement: from bibliometrics to influmetrics. Revista española de documentación cientifica, 18(2), 172-177.

Da Vinci, L. (1970). Philosophical maxims, morals, polemics and speculations. In: Richter, J. P. The notebooks of Leonard da Vinci in two volumes. New York: Dove Publications. Compiled and edited from the original manuscripts by Jean Paul Richter.

Desrochers, N., et al. (2018). Authorship, citations, acknowledgments and visibility in social media: symbolic capital in the multifaceted reward system of science. Social science information, 57(2), 223-248.

Diamond Jr., A. M. (1986). The life cycle research productivity of mathematicians and scientists.Journal of gerontology, 41(4), 520-525.

Dresch, S.P., Janson, K. (1987). Giants, pygmies, and the social costs of fundamental research or Price revisited. Technological forecasting and social change, 32, 323-340.

Egghe, L. (2008). How Derek de Solla Price influenced my work. Research trends, 7, 3-4.

Garfield, E. (1984). A tribute to Derek de Solla Price: a bold, iconoclastic historian of science. Essays of information scientist, 7, 213-217.

Garfield, E. (1985). In tribute to Derek de Solla Price: a citation analysis of little science, big science. Scientometrics, 7, 487-503.

Garfield, E. (2007). From the science of science to Scientometrics: visualizing the history of science with HistCite software. Madrid: Proceedings of ISSI, 1, 21-26, June 25-27.

Glanzel, W. (2008). De Solla Price and the evolution of Scientometrics. Research trends, 7, 4-5.

Goldsmith, M. (1967). The science of science. Science and public policy, 14(1), 12-18.

Goldsmith, M. (1983). Derek de Solla Price (1922-1983). Science and public policy, 10(6), 318.

Griffith, M. (1983). Derek de Solla Price: 1922-1983. 4S Review, 1(4), 2-4

Griffith, B. C. (1984). Derek Price (1922-1983) and the social studies of science. Scientometrics, 6(1), 5-7.

Gusenbauer, M. (2019). Google Scholar to overshadow them all? Comparing the sizes of 12 academic search engines and bibliographic databases. Scientometrics, 118(1), 177-214.

Halevi, G., Moed, H. \& Bar-Ilan, J. (2017). Suitability of Google Scholar as a source of scientific information and as a source of data for scientific evaluation - Review of the literature. Journal of informetrics, 11(3), 823-834.

Hamann, J. (2016). Let us salute one of our kind: how academic obituaries consecrate research biographies. Poetics, $56,1-14$.

Hayashi, M. C. P. I. (2018). Agradecimentos em artigos científicos: o ponto de vista dos pesquisadores. Prisma.com, 37, 55-70.

Hayashi, M. C. P. I., Bello, S. F (2014). Presença dos agradecimentos em um periódico da área da Saúde. Em questão, 20(3), 166-193.

Heffner, A. G. (1979). Authorship, recognition of subordinates in collaborative research. Social studies of science, 9(3), 377-384. 
Irvine, J. \& Martin, B. R. (1985). Evaluating big science: CERN's past performance and future prospects. Scientometrics, 7(3-6), 281-308.

Kaplan, N. (1965). The norms of citation behavior: Prolegomena to the footnote. American documentation, 16(3), 179-184.

Kochen, M. (1984). Toward a paradigm for information science: the influence of Derek de Solla Price. Journal of the American Society for Information Science, 35(3), 147-148.

Kochen, M. (1987). How well do we acknowledge intellectual debts? Journal of documentation, 43(1), 54-64.

La Rochefoucauld, F. D. de. (c1917). Maxims of Le Duc de La Rochefoucauld. Boston: International Pocket Library. Translated by John Heard.

Latour, B. (1987). Science in action: how to follow scientists and engineers through society. Cambridge, MA: Harvard University Press.

Macfarlane, B. \& Chan, R. Y. (2014). The last judgement: exploring leadership in higher education through academic obituaries. Studies in high education, 39(2), 294-306.

Mackay, A. (1984). A. Derek John de Solla Price: an appreciation. Social studies of science, 14, 315-320.

McCain, K. W. (1991). Communication, competition and secrecy: the production and dissemination of researchrelated information in Genetics. Science, technology \& human values, 16, 491-516.

McCain, K. W. (2008). The invisible college: working within the Pricean tradition. Research trends, 7, 8.

Merton, R. K. (1973). The sociology of science: theoretical and empirical investigation. Chicago: University of Chicago Press.

Merton, R. K. (1988). The Matthew effect in science II: cumulative advantage and the symbolism of intellectual property, Isis, 79, 606-2.

Merton, R. K. \& Garfield, E. (1987). Foreword to little science, big science... and beyond. Essays of an information scientist, 10, 73-4.

Michaelis, A. R. (1984). In memoriam: Derek de Solla Price. Bulletin of the Scientific Instrument Society, 2, 9.

Moed, H. (2008). Why "The citation cycle" is my favorite de Solla Price paper. Research trends, 7, 9.

Patel, N. (1973). Collaboration in the professional growth of American sociology. Social science information, 12, 7792.

Pizzani, L. Silva, R. C. \& Hayashi, M. C. P. I. (2012). A arte da pesquisa bibliográfica na busca do conhecimento. Revista digital de biblioteconomia e ciência da informação, 10, 53-66.

Price, D. de S. (1961). Science since Babylon. New Haven, Conn.: Yale University Press.

Price, D. de S. (1963). Little Science, big science. New York: Columbia University Press.

Price, D. de S. (1965). Networks of scientifc papers: the pattern of bibliographic references indicates the nature of the scientific research front. Science, 149 (3683), 510-515.

Price, D. de S. (1969). Measuring the size of science. Proceedings of the Israel Academy of Sciences and Humanities, 4(6), 98-111.

Price, D. de S. (1971). Some remarks on elitism in information and the invisible college phenomenon in science. Journal of the American Society for Information Science, 22, 74-75.

Price, D. de S. (1976). A general theory of bibliometric and other cumulative advantage processes. Journal of the American Society for Information Science, 27, 292-306.

Price, D. de S. (1986). Little science, big science... and beyond. New York: Columbia University Press.

Price, D. de S. \& Beaver, D. de B. (1966). Collaboration in an invisible college. American psychologist, 21, 1011-1018.

Putnam, R. D. (2000). Bowling alone: the collapse and revival of American community. New York: Simon \& Schuster.

Rabkin, Y. M. (1987). Technological innovation in science: the adoption of infrared spectroscopy of chemists. Isis: $A$ Journal of the History of Science, 78, 31-54.

Rossiter, M. W. (1986). Women in the history of scientific communication. The journal of library history, 21(1), 39-59. 
Rossiter, M. W. (1993). The Mathew/Matilda Effect in Science. Social studies of science, 23(2), 325-341.

Scientometrics. (1984). In memorian: Derek de Solla Price, 6(1), 3.

Silva, M. R.; Hayashi, C. R. \& Hayashi, M. C. P. I. (2011). Análise bibliométrica e cientométrica: desafios para especialistas que atuam no campo. InCID: revista de ciência da informação e documentação, 2, 110-119.

Simms, D. L. (1990). The trail for Archimedes's tomb. Journal of the Warburg and Courtauld Institutes, 53, 281-286.

Social Studies of Science. (1983). Derek de Solla Price (1922-83), 13(4), ii.

Steinacker, I. (1984). Derek de Solla Price. Journal of the American Society for Information Science, 35(6), 372.

The New York Times. (1983). Derek J. de Solla Price, professor at Yale dies, 4, Sept.

Turner, G. L. (1984). Obituary Derek John de Solla Price 1922-1983. Annals of science, 41, 105-107.

Van Helden, A. (1977). The invention of telescope. Transactions of the American Philosophical Society, 67(4), 1-67.

Van Raan, A. (2008). Plus ça change, plus c'est la meme chose: de Solla Price legacy and the changing face of scientometrics. Research trends, 7, 10-11.

Yagi, E.; Badash, L. \& Beaver, D. de B. (1996). Derek J. de S. Price (1922-83): historian of science and herald of scientometrics. Interdisciplinary science reviews, 21(1), 64-84. 